\title{
Ergonomic Assessment of Computer Workstation At Federal University of Technology Owerri Nigeria
}

\author{
1,3 * Onoh, C.C $;{ }^{1}$ Aguocha, J.K $;{ }^{1}$ Osuagwu,I.K; ${ }^{3}$ Akalonu,G.I; ${ }^{2}$ Amadi, C.O; \\ ${ }^{2}$ Nwufo,C.R; ${ }^{3}$ Nwachuku, C.I \\ ${ }^{I}$ Department Of Health Services, Federal University Of Technology, Owerri, Nigeria \\ ${ }^{2}$ Department Of Public Health, Federal University Of Technology, Owerri, Nigeria \\ ${ }^{3}$ Centre For Occupational Health, Safety \& Environment, University Of Port Harcourt,Nigeria
}

\begin{abstract}
Ergonomics is the fixing of the job to man, adapting the job to fit the worker. It is the human-machine interface whose ultimate goal is the humanization of work and increasing the facets of productivity: effectiveness, efficiency and quality. This Study was designed to determine the various types of Work related musculoskeletal disorders among Computer operators and the Noise pollution levels at Federal University of Technology Computer Workstation, Owerri. This was a work-site based cross sectional study involving 150 consenting Computer operators. Data were collected through Questionnaire and measurements of noise levels. The Questionnaire were structured, self-administered and of two parts. The first part addressed the Sociodemographic variables with respect to age, gender and marital status whereas the second part was designed to determine the prevalence rates of various types of Work related musculoskeletal disorders of the participants. The prevalence was determined as a rate and reported in percentages. The Noise pollution levels were determined by measuring the Noise levels of the Computer Workstation Site using an Audio-digital Sound Meter Model JTS- 1357. It offered a resolution of $0.1 \mathrm{~dB}$ with an accuracy of $\pm 1.5 \mathrm{~dB}$ (94dB @ $1 \mathrm{KHz})$. Noise levels were reported in Equivalent continous noise levels (Leq), a Logarithm-based Scale. Data were entered into Microsoft Excel Spreadsheet version 2010 to IBM-SPSS statistics version 21 for analysis. High prevalence rates of $90 \%$ and $83.7 \%$ were reported for Cuboid subluxation and Eye strain respectively among the Computer operators. The Equivalent continous noise level (Leq) for day 1 ranged from 56.86dB(A) on CWS-7 to $58.1 \mathrm{~dB}(A)$ on $\mathrm{CWS}-9$. These were within the permissible range. The Computer Work stations at FUTO were relatively free from the adverse effects of physical noise pollution.
\end{abstract}

\section{Introduction}

Ergonomics (or human factors) is the scientific discipline concerned with the understanding of interactions among humans and other elements of a system, and the profession that applies theory, principles, data and methods to design in order to optimize human well-being and overall system performance (IEA, 2014; IEA, 2015). It is the fixing of the job to man, adapting the job to fit the worker (Dul, 1999). Ergonomics is the science of fitting workplace conditions and job demands to the capabilities of the working population. It improves employee performance and well-being in relation to the job tasks, equipment, and the environment. It is a continuous improvement effort to design the workplace for what people do well and design out what people do not do well. Ergonomics is the fitting of job to the person (Etebu, 2015). It is the human, machine interface whose ultimate goal is the humanization of work and increasing the facets of productivity: effectiveness, efficiency and quality (Fig. 1).

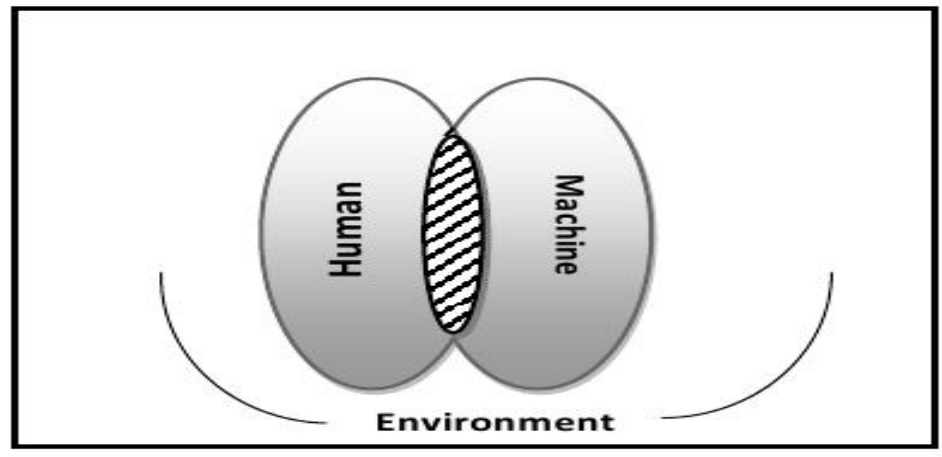

Fig. 1: Human-Machine Interface Source: US Air Force (2015). 
Ergonomic hazards are workplace conditions that pose the risk of injury to the musculoskeletal system of the Computer operator (Shikardar, 2005); like repetitive movement, manual handling, workplace (job/task design, uncomfortable workstation), height and poor body positioning. Ergonomic risk factors are the aspects of a job or task that impose a biomechanical stress on the Computer operator. Thousands of epidemiological studies, laboratory studies, and extensive reviews of the existing scientific evidence by National Institute for Occupational Safety and Health (NIOSH) and National Academy of Science (NAS) shows that the following ergonomic risk factors are most likely to cause or contribute to musculoskeletal disorders: (Awkward postures, prolonged activities on the computer, sitting without foot support, cold or hot temperatures, noise, contact stress, force, repetitive movement, static postures, vibration, unsuitable work flow/methods) ((Dul, 1996; Jennifer, 2012; OSHA,2012).

Workplace is a location where a person performs tasks for a relatively long period of time. It involves observing the employee performing typical tasks, and then adjusting the workstation as needs (such as raising a chair or lowering a keyboard). The goal is to arrange the workstation so that the employee achieves a neutral, comfortable working posture. Computer job is physically demanding and requires long sitting on a chair and is at the greatest risk for both accidental and non - accidental injury. Many people that work on the computer for a long time have neck and back problems because of prolonged sitting and stretching of the neck (OSHA, 2012). A number of factors play a role in ergonomics assessment; these include body posture and movement, sitting, standing, lifting, pulling, pushing and environmental factors: noise, lighting, temperature, and humidity (Dul et al., 1993; Grandjean, 2000).

A Workstation is one of a series of Workplaces that may be occupied or used by the same person sequentially when performing his or her job. It accommodates a computer terminal or other electronic equipment. They are commonly connected to a local area network and run multi-user operating system. Ergonomic assessment of Computer workstation involves the fitting of work place conditions and demands to the capabilities of the workers. It considers the capabilities and limits of workers as they interact with tools, equipment, work methods, and tasks in the environment (McCormick \& Saunders, 1993).

\section{Methodology}

\subsection{Study Area}

This study was carried out in Owerri, the capital of Imo State of Nigeria. It is situated at $5.48^{\circ}$ north latitude, $7.03^{\circ}$ east longitude and 159 meters above sea level land. The population is about 400,000 as at 2006 and covers over $100 \mathrm{~km}^{2}$ in area (NBS, 2010). Owerri is bordered by the Otamiri River to the east and the Nworie River to the South (Onoh \& Nwagozie, 2015; Onoh \& Nwagozie, 2016). Its environment has witnessed an upsurge in the number of banks, hotels, markets, industries, food restaurants, night and social lifestyles (Onoh, 2014). Important educational institutions in Owerri include Imo State University, Federal University of Technology, African Institute of Science and Technology, Federal Polytechnic Nekede, Alvan Ikoku Federal College of Education and so many Secondary schools.

\subsection{Study Site}

This research was carried out at the FUTO Computer Workstation Site located close to the FUTO market (Fig. 2). There are over 60 Computer Workstations with about 240 Computer operators putting on an average of 10 hours per day. The offices are usually congested with very little space to operate. The temperatures of the environment were always very unbearable especially during the hot season of the year (Nkwocha, 2015; Ugo, 2015).

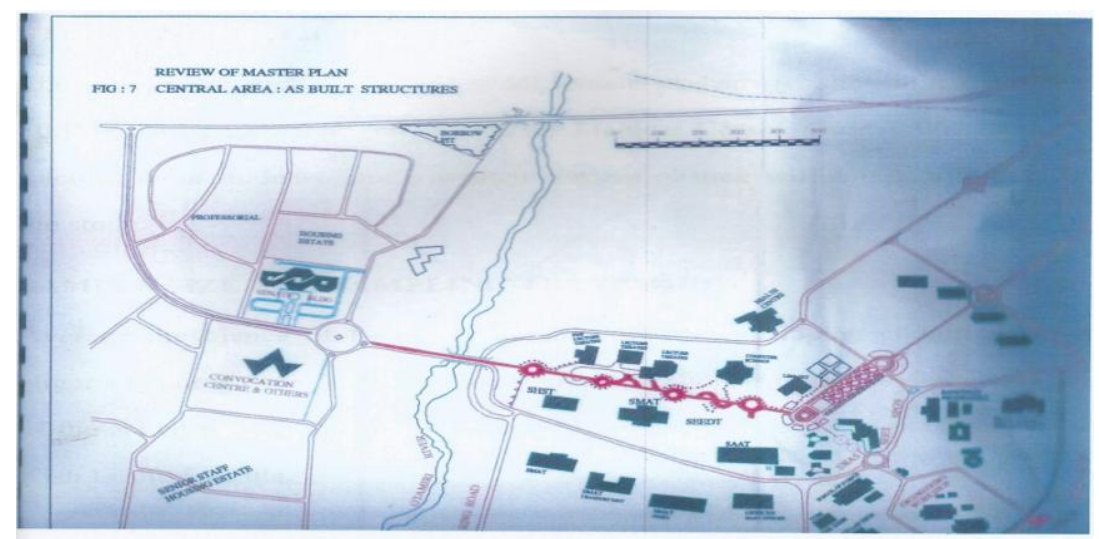

Fig 2: FUTO Master Plan

Source: FUTO Library (2015). 


\subsection{Study Design}

This was a work-site based cross sectional study

\subsection{Study Population}

The Study population comprised of all consenting Computer operators in Federal University of Technology, Owerri. A total of one hundred and fifty Computer operators of Federal University of Technology, Owerri were recruited for the study. The study was conducted over a period of six months starting from May, 2015 to November, 2015 by consecutively recruiting Computer operators at FUTO Computer Workstation, Owerri.

\subsubsection{Inclusion and Exclusion criteria}

The Inclusion criteria were bona fide Computer operators at the FUTO Computer Workstation Site who have worked for more than one year and who gave informed written consent for the study. The Exclusion criteria were Computer operators who suffer Chronic Osteoarthritis, Rheumatoid Arthritis, critically ill or those on medication for these conditions (Punnett \& Wegman, 2004).

\subsection{Sampling Technique}

The Sample selection was done consecutively using every Computer operator at FUTO Computer Workstation who consents to the study and met the inclusion criteria. The Sampling technique was purposively chosen by the researchers based on the fact that the authors believed that those enrolled were likely to be representative of the Study population (Iloh et al; 2016).

\subsection{Methods Of Data Collection}

Data were collected through Questionnaire and Measurement of Noise levels.

\subsubsection{Questionnaire}

The questionnaire design was of two parts. They were structured and self- administered. The first part addresses the background information in form of socio-demographic variables of the participants with respect to age, gender and marital status. Part 2 of the questionnaire was designed to determine the prevalence rates of various types Work Related Musculoskeletal Disorders (WMSDs). The validity and reliability of the questionnaire were tested by renowned and consummate Statisticians which was found to be suitable for the study.

\subsubsection{Measurement of Noise Levels}

The Noise levels were measured in the morning, afternoon and evening of the five working days of the week (Monday to Friday). The characteristic "A" weighting was simulated since this was the Human ear listening response recommended by Standards (Aguiluz, 2003; OSHA, 1993; OSHA, 2001). Several measures were made on these days and the Equivalent continuous noise level (Leq) was calculated using Equation (2).

The Equivalent Continuous Noise Level $\left(\mathrm{L}_{\mathrm{eq}}\right)$ is the preferred method to describe sound levels that vary over time, resulting in a single decibel value which takes into account the total sound energy over the period of time of interest. It is used to allow for fluctuating noise over a given time period. The Equivalent continuous noise level $\left(\mathrm{L}_{\mathrm{eq}}\right)$ is defined as the Sound Pressure Level in $\mathrm{dB}(\mathrm{A})$ of a steady sound that has the same energy as the total energy of a fluctuating sound over a given period of time( Breysee \& Lees, 2006).

$$
\begin{aligned}
& L_{e q}=10 \log _{10}\left(\frac{t_{1}}{T} x 10^{L_{1} / 10}\right)+10 \log _{10}\left(\frac{t_{2}}{T} x 10^{L_{2} / 10}\right)+\cdots+10 \log _{10}\left(\frac{t_{n}}{T} x 10^{L_{n} / 10}\right) \\
& L_{e q}=10 \log _{10}\left(\frac{t_{1}}{T} x 10^{L_{1} / 10}+\frac{t_{2}}{T} x 10^{L_{2} / 10}+\cdots \frac{t_{n}}{T} x 10^{L_{n} / 10}\right)
\end{aligned}
$$

where $L_{1}, L_{2}, \ldots L_{n}$ are the instantaneous noise level (dBA),

$$
\begin{aligned}
& t_{1}, t_{2}, \ldots t_{n} \text { are the time for which } L_{1}, L_{2}, L_{n} \text { occurred, and } \\
& \mathrm{T}=t_{1}+t_{2}+\ldots+t_{n}
\end{aligned}
$$

If $t_{1}=t_{2}=t_{n}$, then

$L_{e q}=10 \log _{10} \sum_{i=1}^{n}\left(\frac{t_{1}}{T} \times 10^{L_{1} / 10}\right)$ 
The Noise level was measured using an Audio-Digital Sound Meter Model JTS- 1357. It weighed 0.9kg with a dimension of $95 \times 277 \times 59 \mathrm{~mm}$. It has an accuracy of $\pm 1.5 \mathrm{~dB}(94 \mathrm{~dB} @ 1 \mathrm{KHz})$ and a sampling rate of 2 to 5 times per second. It has an auto-peak hold and a resolution of $0.1 \mathrm{~dB}$, ranging from $30-130 \mathrm{~dB}(\mathrm{~A}) ; 35-130 \mathrm{~dB}(\mathrm{C})$.

\section{Data Analysis}

Data were entered into Microsoft Excel Spreadsheet version 2010 and transferred to IBM-SPSS Statistics version 21 for analysis. The results of the analysis were presented in tables, frequencies, percentages and charts. The Prevalence was calculated in rates and reported as percentages. Frequency distribution was computed for class variables and were all expressed as percentage of the distribution, which were presented on a distribution table. The Noise levels were measured in " A" weighted frequency and recorded in decibels $[\mathrm{dB}(\mathrm{A})]$. Leq was calculated using the Logarithmn Formula Equation (2).

\section{Results}

A total of 150 Computer operators were examined at FUTO Computer Workstation. There were more male Computer operators than female. Of the entire 150 Computer operators, $57 \%$ (85 out of 150) were males and $43 \%$ (65 out of 150) were females (Fig. 3).

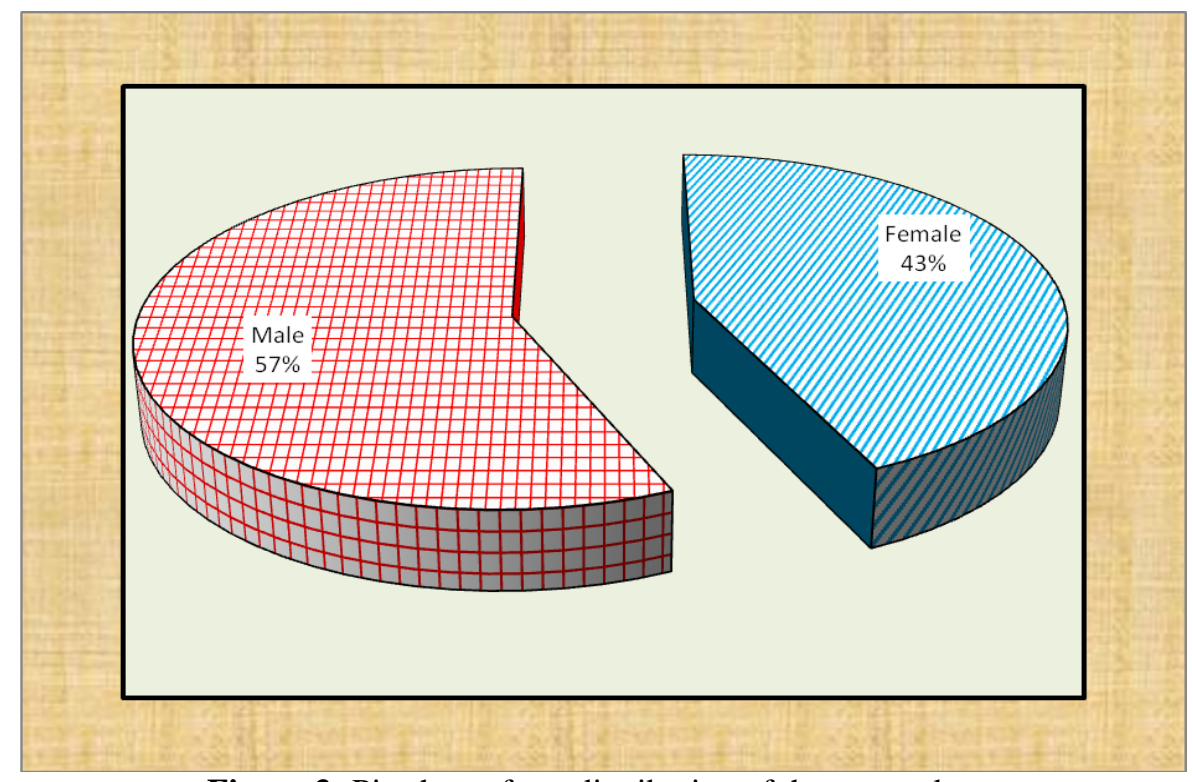

Figure 3: Pie chart of sex distribution of the respondents

Table1: The Prevalence of various types of Musculoskeletal Disorders among the Computer operators at FUTO Computer

Workstation.

\begin{tabular}{|l|l|l|l|}
\hline Types of Musculoskeletal Disorders & \multicolumn{2}{|c}{$\begin{array}{l}\text { on } \\
\text { Musculoskeletal Disorders }\end{array}$} & \multirow{2}{*}{ Total } \\
\cline { 2 - 3 } & Yes $(\%)$ & No $(\%)$ & $150(100)$ \\
\hline Tennis Elbow \{Pain In The Elbow) & $95(63.3)$ & $55(36.7)$ & $150(100)$ \\
\hline Stenosing Tenosynovitis (Pain In The Fingers) & $100(66.7)$ & $50(33.3)$ & $150(100)$ \\
\hline Rotator Cuff Syndrome (Pain In The Shoulder) & $85(56.7)$ & $65(43.3)$ & $150(100)$ \\
\hline Tension Neck Syndrome (Pain In The Neck) & $110(73.3)$ & $40(26.7)$ & $150(100)$ \\
\hline Patellofemoral Pain (Pain In The Knees) & $120(80.0)$ & $30(20.0)$ & $150(100)$ \\
\hline Eye Strain (Pain In The Eyes) & $125(83.3)$ & $25(16.7)$ & $150(100)$ \\
\hline Low Back Pain (Pain In The Back) & $100(66.7)$ & $50(33.3)$ & $150(100)$ \\
\hline $\begin{array}{l}\text { Carpal Tunnel Syndrome (Pain In The Heel } \\
\text { Sides) }\end{array}$ & $120(80.0)$ & $30(20.0)$ & $150(100)$ \\
\hline Cuboid Subluxation (Pain In The Sole of the foot) & $135(90.0)$ & $15(10.0)$ & Chi square=71.591, df=8, p-value= 0.000 \\
\hline Statistical test & \multicolumn{2}{|l}{} \\
\hline
\end{tabular}

For Tennis elbow (pain in the elbow) complain among the Computer operators, 95 (63.3\%) responded that they do have Tennis elbow compared to $55(36.7 \%)$ who responded that they do not have it. Hence the prevalence of Tennis elbow was found to be $63.3 \%$ among Computer operators at FUTO Workstation (Table 1). 


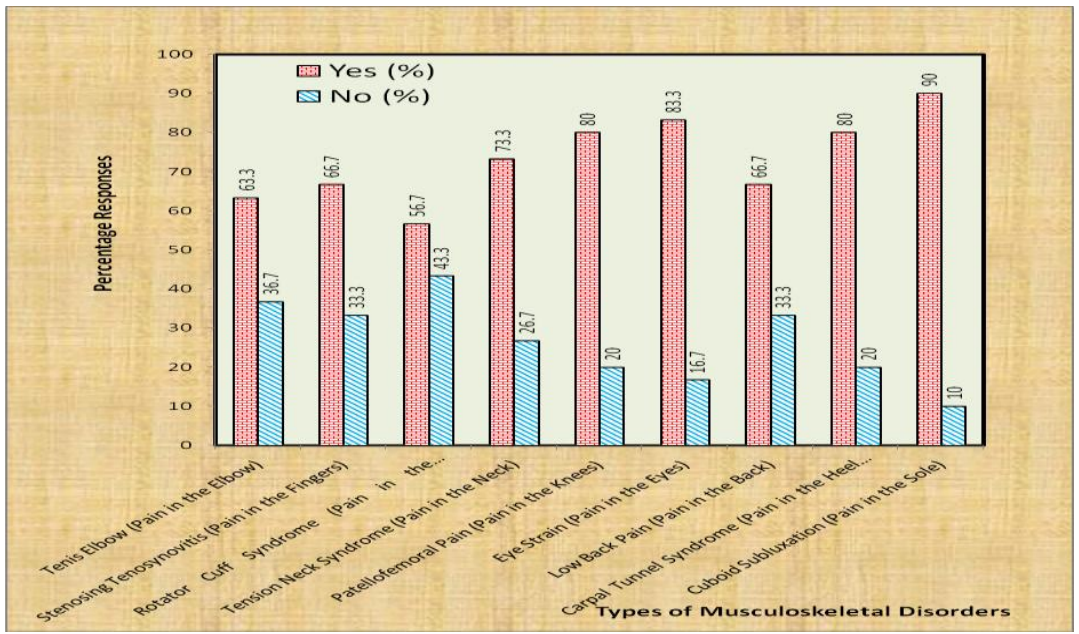

Figure 4: Responses on various types of Work Related Musculoskeletal Disorders (WMSD) among FUTO Computer operators

For the prevalence studies, the Bar Chart (Fig. 4) clearly indicates that Stenosing Tenosynovitis -Pain in the fingers showed 66.7\%. Others are: Rotator Cuff Syndrome -Pain in the shoulder (56.7);Tension Neck Syndrome -Pain in the neck (73.3\%); Patellofemoral Pain -Pain in the knees (80\%); Eye Strain -Pain in the eyes (83.3\%); Low Back Pain- Pain in the back (66.7); Carpal Tunnel Syndrome-Pain in the Heel Sides (80\%); Cuboid Subluxation-Pain in the Sole of the foot: (90\%). While 56.7\% complained of Rotator Cuff Syndrome (Pain in the Shoulder), up to 90\% complained of Cuboid Subluxation (Pain in the Sole of the foot).

The Noise levels were measured three times per day: morning between 9am and $11 \mathrm{am}$, afternoon between 12noon and $2 \mathrm{pm}$, evening between $4 \mathrm{pm}$ and $6 \mathrm{pm}$. During the morning hours $(9 \mathrm{am}-11 \mathrm{am})$, noise level ranged from $51.2 \mathrm{~dB}(\mathrm{~A})$ at CWS-5 to $56.5 \mathrm{~dB}(\mathrm{~A})$ at CWS-7. In the afternoon hours (12noon - 2pm) noise level ranged from $55.5 \mathrm{~dB}$ (A) at CWS-7 to $59.9 \mathrm{~dB}$ (A) while during the evening hours (4-6pm), noise level ranged $57.7 \mathrm{~dB}$ (A) at CWS-4 to $59.9 \mathrm{~dB}$ (A) at CWS-1(Table 2). The Equivalent continuous level for the Day-1ranged from 56.86dB (A) on CWS-7 to 58.1dB (A) on CWS-9 (Fig.5; Table 2). The results showed that Equivalent continuous noise levels were within the permissible noise level of $85 \mathrm{~dB}(\mathrm{~A})$ for an 8-hour working day (OSHA, 1993). In conclusion, the 10-CWS's Sample on Day-1 was within the safe working environment by the appropriate Standards (OSHA,2001).

Although this study showed that the Computer Workstation at FUTO were relatively free from the adverse effects of physical noise pollution, other health effects of noise pollution not captured in this study cannot be ruled out.

Table 2: Calculated Equivalent Noise Levels of Various Computer Workstations(CWS).

\begin{tabular}{|l|l|l|l|l|}
\hline $\begin{array}{l}\text { Location } \\
\text { Code }\end{array}$ & Morning & Afternoon & Evening & $\begin{array}{l}\mathbf{L}_{\text {eq, }} \\
\text { dB(A) }\end{array}$ \\
\hline CWS-1 & 51.3 & 58.7 & 59.9 & 57.9 \\
\hline CWS-2 & 52.3 & 58.9 & 58.5 & 57.4 \\
\hline CWS-3 & 54.1 & 58.7 & 58.7 & 57.6 \\
\hline CWS-4 & 52.1 & 58.7 & 57.7 & 57.0 \\
\hline CWS-5 & 51.2 & 58.5 & 58.0 & 56.9 \\
\hline CWS-6 & 52.4 & 58.2 & 58.3 & 57.0 \\
\hline CWS-7 & 56.5 & 55.5 & 58.0 & 56.8 \\
\hline CWS-8 & 52.4 & 59.6 & 58.3 & 57.7 \\
\hline CWS-9 & 54.2 & 59.9 & 58.5 & 58.1 \\
\hline CWS-10 & 54.4 & 58.3 & 58.3 & 57.3 \\
\hline CWS-11 & 51.2 & 52.3 & 58.7 & 55.4 \\
\hline CWS-12 & 52.4 & 55.2 & 58.3 & 56.0 \\
\hline CWS-13 & 54.2 & 55.5 & 58.0 & 56.2 \\
\hline CWS-14 & 52.4 & 55.3 & 58.3 & 56.0 \\
\hline CWS-15 & 55.3 & 54.9 & 58.0 & 56.3 \\
\hline CWS-16 & 54.2 & 55.5 & 58.3 & 56.3 \\
\hline CWS-17 & 55.1 & 55.5 & 58.1 & 56.4 \\
\hline CWS-18 & 54.2 & 55.0 & 58.3 & 56.2 \\
\hline CWS-19 & 52.1 & 54.2 & 58.0 & 55.5 \\
\hline CWS-20 & 52.0 & 55.0 & 58.1 & 55.7 \\
\hline CWS-21 & 52.0 & 58.9 & 58.1 & 57.2 \\
\hline CWS-22 & 50.0 & 55.1 & 55.9 & 54.3 \\
\hline CWS-23 & 52.1 & 58.9 & 55.9 & 56.5 \\
\hline
\end{tabular}


Ergonomic Assessment of Computer Workstation At Federal University ...

\begin{tabular}{|l|l|l|l|l|}
\hline CWS-24 & 50.1 & 55.0 & 55.5 & 54.1 \\
\hline CWS-25 & 51.1 & 56.2 & 57.0 & 55.4 \\
\hline
\end{tabular}

\begin{tabular}{|l|l|l|l|l|}
\hline $\begin{array}{l}\text { Location } \\
\text { Code }\end{array}$ & Morning & Afternoon & Evening & $\begin{array}{l}\mathbf{L}_{\text {eq }} \\
\text { dB(A) }\end{array}$ \\
\hline CWS-26 & 55.1 & 55.0 & 55.5 & 55.2 \\
\hline CWS-27 & 51.0 & 54.2 & 56.9 & 54.7 \\
\hline CWS-28 & 51.2 & 52.3 & 55.9 & 53.6 \\
\hline CWS-29 & 50.0 & 52.2 & 55.3 & 53.0 \\
\hline CWS-30 & 53.1 & 53.1 & 55.5 & 54.1 \\
\hline CWS-31 & 50.1 & 55.5 & 55.3 & 54.2 \\
\hline CWS-32 & 51.3 & 55.1 & 55.5 & 54.3 \\
\hline CWS-33 & 50.1 & 52.4 & 55.3 & 53.1 \\
\hline CWS-34 & 52.0 & 55.5 & 56.3 & 55.0 \\
\hline CWS-35 & 50.1 & 54.2 & 55.3 & 53.7 \\
\hline CWS-36 & 51.1 & 50.1 & 55.3 & 52.8 \\
\hline CWS-37 & 53.1 & 53.3 & 55.3 & 54.0 \\
\hline CWS-38 & 50.1 & 55.5 & 55.3 & 54.2 \\
\hline CWS-39 & 52.2 & 55.3 & 55.3 & 54.5 \\
\hline CWS-40 & 50.1 & 56.1 & 55.3 & 54.5 \\
\hline CWS-41 & 51.1 & 55.5 & 55.3 & 54.4 \\
\hline CWS-42 & 54.0 & 54.2 & 55.5 & 54.6 \\
\hline CWS-43 & 51.0 & 55.3 & 55.5 & 54.4 \\
\hline CWS-44 & 50.1 & 56.2 & 55.5 & 54.6 \\
\hline CWS-45 & 52.3 & 55.9 & 55.9 & 55.0 \\
\hline CWS-46 & 50.1 & 59.3 & 55.3 & 56.3 \\
\hline CWS-47 & 53.3 & 55.1 & 55.6 & 54.8 \\
\hline CWS-48 & 53.4 & 59.1 & 55.5 & 56.6 \\
\hline CWS-49 & 55.4 & 55.1 & 56.9 & 55.9 \\
\hline CWS-50 & 50.1 & 59.2 & 57.3 & 56.9 \\
\hline
\end{tabular}

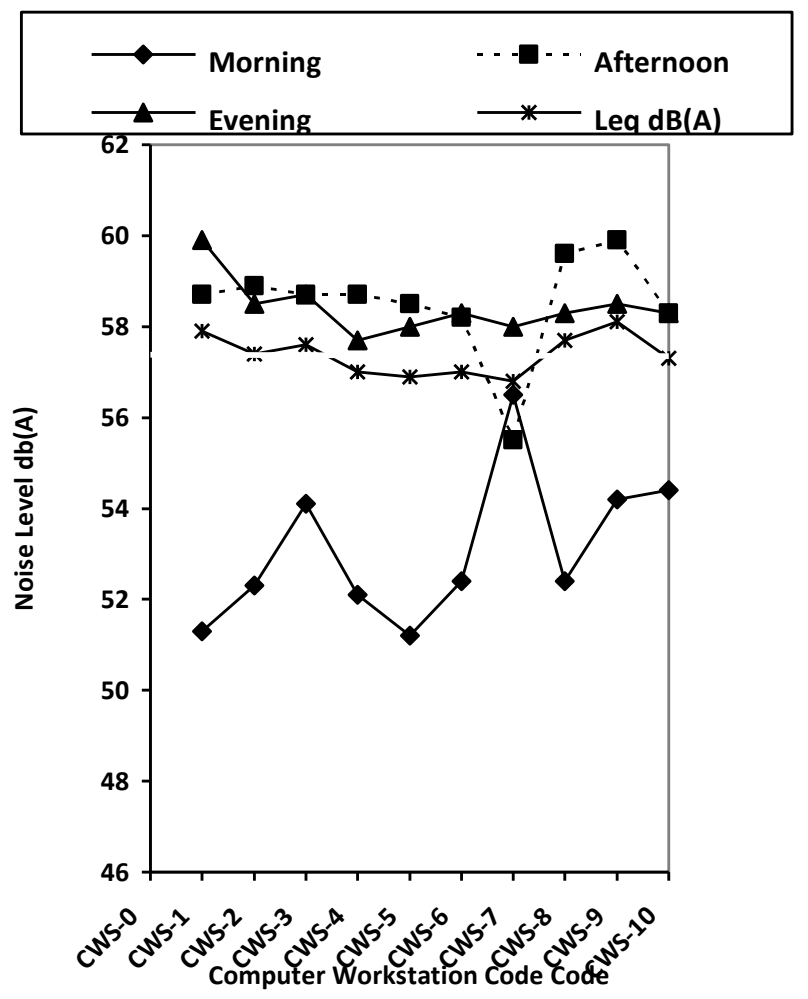

Fig. 5: Noise level distribution for Day 


\section{Discussion}

Findings of this research study showed that the Computer operators of Federal University of Technology, Owerri suffered numerous Work-related musculoskeletal disorders (WMSD). These include Cuboid Subluxation (pain in the sole of the foot), Eye strain, Carpel tunnel syndrome, Patellofemoral syndrome, Tension Neck syndrome, Stenosing Tenosynovitis, Rotator Cuff syndrome, Low Back pain and Tennis Elbow. The most prevalent is Cuboid Subluxation with a prevalence rate of $90 \%$. The second is Eye strain with prevalence rate of $83.37 \%$, followed by Carpel tunnel and Patellofemoral syndromes with prevalence rate of $80 \%$.

Cuboid subluxation is the most prevalent WMSD among operators in FUTO Computer Workstation, Owerri. Cuboid subluxation is thought to arise from subtle disruption of the artherokinematics or structural congruity of the Calcaneocuboid (CC) joint (Durall, 2011). Weight, prolonged sitting, certain stress and movements of the foot and ankle places a lot of stress on the cuboid bone through the Peroneus longus muscles. Excess forces put a strain on the surrounding Soft and Connective tissues which may cause pain and tearing. This may allow the cuboid bone to sublux or partially move out of its normal alignment relative to the adjacent foot bones. This subtle disruption of the arthrokinematics of the Calcaneocuboid joint suggests the pathomechanic mechanism of cuboid subluxation (Durall, 2011).

There were numerous ergonomic hazards in the Computer workstation. They are usually congested, poor workplace design and layout leading to awkward postures; Inappropriate handling or manual handling of tasks; Excessive reaching, stretching and bending; Insufficient rest breaks; Excessive repetitive movements; Unsuitable workflow/methods; Unpadded office seats (Dul, 2002; Jim,2002; Kelvin \& Hicok, 2006; Jeniffer, 2012).

During the morning hours (9am-11am), noise level ranged from 51.2 dB (A) at CWS-5 to 56.5dB (A) at CWS-7. In the afternoon hours (12noon - 2pm) noise level ranged from 55.5dB (A) at CWS-7 to $59.9 \mathrm{~dB}(\mathrm{~A})$ while during the evening hours (4-6pm) noise level ranged $57.7 \mathrm{~dB}(\mathrm{~A})$ at CWS-4 to $59.9 \mathrm{~dB}$ (A) at CWS-1. In general, the noise level was lowest in the morning hours, followed by afternoon and evening. The equivalent continuous level for the Day - ranged from $56.86 \mathrm{~dB}$ (A) on CWS-7 to 58. 1dB (A on CWS-9).

The results showed that Equivalent continuous noise levels were within the permissible noise level of $85 \mathrm{~dB}$ (A) for an 8-hour working day. The NIOSH recommended exposure limit (REL) for Occupational noise exposure is 85 decibels, A-weighted, as an 8-hr time-weighted average (TWA) ( 85 dBA as an 8-hr TWA). Exposures at and above this level are considered hazardous (OSHA, 1993; OSHA,2001). The Computer Workstations at FUTO were relatively free from the adverse effects of physical noise pollution as recommended by these Standards.

\section{Study Implications}

Noise is excessive or unwanted sound which potentially results in annoyance and/or hearing loss from occupational or non-occupational sources (Breysse \& Lees, 2006). We cannot measure acoustic energy, but we can measure Sound Pressure Levels very well. Sound is a pressure variation (wave) that travels through air and is detected by the human ear. The relationship between acoustic energy and Sound Pressure is LogarithmBased. Thus, sound pressure is a surrogate for acoustic energy. The focus of Noise measurement is to prevent Hearing loss associated with noise exposure. Decibel (dB) is a Log-based scale developed to quantify sound. Summation of Sound Pressure Levels (SPL) follows the rule of thumb: Adding two Sound Pressure Levels of equal value will always result in a $3 \mathrm{~dB}$ increase. This is because Decibel $(\mathrm{dB})$ is a Logarithm Based Scale (LBS). Thus, it is of advantage that in humans, the Decibel summation only results in minimal increase in noise level. Moreover, it is extremely difficult to reduce noise exposure in industries. Guarding and Sound-Proofing materials make machines hard to clean and noise reduction very expensive. Furthermore, Hearing protection is not very effective because it is often not used properly and is uncomfortable to wear (Breysee \& Lees, 2006).

Although this study showed that the Computer Workstation at FUTO were relatively free from the adverse effects of physical noise pollution, other health effects of noise pollution not captured in this study cannot be ruled out.

\section{Conclusion}

This study has established a very high prevalence of Cuboid subluxation as a WMSD among Computer operators in FUTO Workstation. The prevalence was found to be 90\%. The second most prevalent WMSD was Eye strain which recorded a prevalence rate of $83.37 \%$ followed by Carpel Tunnel and Patellofemoral syndromes with prevalence rate of $80 \%$ each. The noise levels were lowest in the morning hours, followed by afternoon and evening. The Equivalent continuous noise level for the Day - ranged from 56.86dB (A) on CWS7 to 58 . $1 \mathrm{~dB}$ (A) on CWS-9. The results showed Equivalent continuous noise levels were within the permissible. The Computer Work stations at FUTO were relatively free from the adverse effects of physical noise pollution. 


\section{Ethical Clearance}

Ethical clearance was granted by the Chairman of Research \& Ethics Committee, Department of Public Health, Federal University of Technology, Owerri. All information shared during the research were strictly confidential and protected by the law of confidentiality. The identity, privacy, and confidentiality of all who consented to participate were protected. This Study was carried out in compliance with internationally accepted Legal and Ethical requirements in Human Research.

\section{Recommendation}

The following recommendations were made based on the findings from the Study:

i) The University management should create awareness among the Computer operators to imbibe and apply the Principles of Ergonomics in the Workplace as this will help to reduce the whole lot of ergonomic hazards that are abound in the Computer Workstations.

ii) The Computer operators should form Cooperative Societies and with the assistance of the University management make provision for a Computer pool. This will go a long way in militating against the risk factors.

iii) The Office seats should have back rest and must be provided with protective padding so as to absorb vibrations, maintain the position of the Cuboid bone and reduce the transmission of weight to the lower limbs. There should be Foot Support on an even surface.

iv) For Cuboid Subluxation and other Arthrokinematic injuries, First Aid treatment and early Rehabilitation process should be implemented. The R.I.C.E regimen should be adopted; R- Rest from aggravating activities as to reduce swelling and inflammation; Ice: Icing the affected site regularly; C: Compressing the affected areas with Compression bandages and E: Elevation of the affected limb. The so called RICE regimen is a rehabilitative process to prevent stiffness and weakness from developing and to ensure that the foot and ankle are functioning adequately.

v) Anti-inflammatory medication especially the Non-steroidal anti-inflammatory drugs (NSAID) in form of cream, jelly or sprays may be applied on the affected parts.

vi) The most effective way to combat Eye strain is to install an antiglare, non-adhesive screen Protectors on the Computers.

vii) The Computer operators should take frequent short breaks of 30 minutes intervals, a sort of periodic "mini breaks". This reduces tension and relaxes the muscles. This does not mean that work should be stopped but work type could be rotated as to avoid a repetitive movement which is a strong risk factor for WMSDs (OSHA, 2012).

\section{References}

[1]. Aguiluz, D.O.A \& Arnold, F (2003). The Occupational Environment, its evaluating control and management . $2^{\text {nd }}$ Ed

[2]. Breysse, P.N.E \& Lees, P.S.J. (2006). Noise. Johns Hopkins Bloomberg University, School of Public Health.

[3]. Dul, S. (1996). Ergonomics for Beginners. Journal of Medicine and Occupational health, 55:320-340.

[4]. Dul, S. (1999). Ergonomic assessment interventions strategies of computer workstations. Journal of Medicine and Science, 62(4): $118-142$

[5]. Dul, S. (2002). Risk Factor Musculoskeletal. Journal of Medicine and Health, 54(3):130-172.

[6]. Dul, S., Shikardar, G. Harry, C. (1993). Ergonomic design for modern workstation. Journal of Medicine and Health, 90 (10):125135.

[7]. Dul, S., \& Swanson, P. (2008). Health Hazard Management. Journal of Medicine and Science 60 (4):130-170.

[8]. Durall, C.I. (2011). Examination \& Treatment of Cuboid Syndrome: A Literature review. Sports Health; 3(6): 514-519.

[9]. Etebu, O.M.O. (2015). Personal Communication, Dean, Faculty of Engineering, University of Port Harcourt, Nigeria.

[10]. Grandjean, E. (2000). Measurement and Design of workplace, Journal of Medicine and Health 38(4): $372-384$.

[11]. IEA, (2014). Ergonomics, science and human health. International journal of Ergonomics and Health, 23(5):34-59.

[12]. IEA, (2015). Definition of Ergonomics. Journal of Occupational Health and Safety, 48, 322-406.

[13]. Iloh, G.U.P; Amadi, A.N; \& Amadi, C.O.A. (2016). Metabolic syndrome in a Sub-population of Geriatric Nigerians in a Primary care Clinic of a Tertiary Hospital in South-Eastern Nigeria. British Journal of Medicine \& Medical Research; 13(5): 1-12.

[14]. Jennifer A. (2012). Recent Epidemiological Studies of workplace musculoskeletal Disorder. Journal of Occupation and safety 50, 120-168.

[15]. Jim, G. (2002). The definition and causes of Musculoskeletal Disorder. Journal of Medicine and Science, 20, 59-172.

[16]. Kelvin, T. \& Hicok, G. (2006). Ergonomic intervention for musculoskeletal disorders. Journal of Occupation and Medicine, 64(4):180-178.

[17]. McCormick, J. and Saunders, M.S. (1993). Assessment of computer workstation and arrangement and layout. Journal of Medicine and Health, 50 (30): 33-64.

[18]. NBS (2015). National Bureau of Statistics. Annual Abstract of Statistics. Federal Government of Nigeria.

[19]. Nkwocha, C.V. (2015). Ergonomic Assessment of Computer Workstation in Federal University of Technology, Owerri.Post Graduate Diploma Thesis; Department of Public Health, Federal University of Technology, Owerri, Nigeria.

[20]. Onoh, C.C. (2014). Workplace Health Assessment of Hypertension and Diabetes in Some Selected Manufacturing Industries in Owerri, South Eastern, Nigeria. M.Sc. Thesis; University of Port-Harcourt, Rivers State, Nigeria. Pp.92-112.

[21]. Onoh, C.C. \& Nwaogazie, I.L (2015). Assessment of Diabetes: Prevalence and Prediction of Risk Development in a Manufacturing Industry in Owerri, Nigeria. International Journal of Current Advanced Research Vol.4, (8): 341-346. Available @ http.//journalijcar.org 
[22]. Onoh, C.C. \& Nwaogazie, I.L. (2016). Workplace Assessment of Hypertension: Prevalence and Awareness in a Food Processing Industry in Owerri Nigeria. International Journal of Tropical Disease \& Health 16(4): 1-11.

[23]. OSHA, (1993). United States Department of Labour, Occupational \& Health. Administration Office of Training and Education, OSHA Voluntary compliance outreach programme: Instructors Reference Manual, Des Placies.

[24]. OSHA, 2001). United States Department of Labour, Occupational \& Health. Administration Office of Training and Education Manual for Trainer Courses in OSHA Standards for the General Industry. Des Plaines.

[25]. OSHA, (2012). Periodic "mini break" in workplaces. Journal of occupational safety and Health, 58(4): 80-178

[26]. Punnet, L \& Wegman, D.H. (2004). Work-related muscoskeletal disorder: the epidemiology evidence and the debate. Journal of Electromyography and Kinesiology 14: 13-23.

[27]. Shikardar, G. (2005). Ergonomic methods for assessing exposure to risk factors for working-related musculoskeletal disorders, 68, 107-109.

[28]. Ugo, I.C. (2015). Prevalence of Vulvovaginal candidiasis among female students attending Federal University of Technology, Medical Centre, Owerri, Nigeria. B.Sc. Thesis; Department of Public Health, Federal University of Technology, Owerri. Nigeria. 